
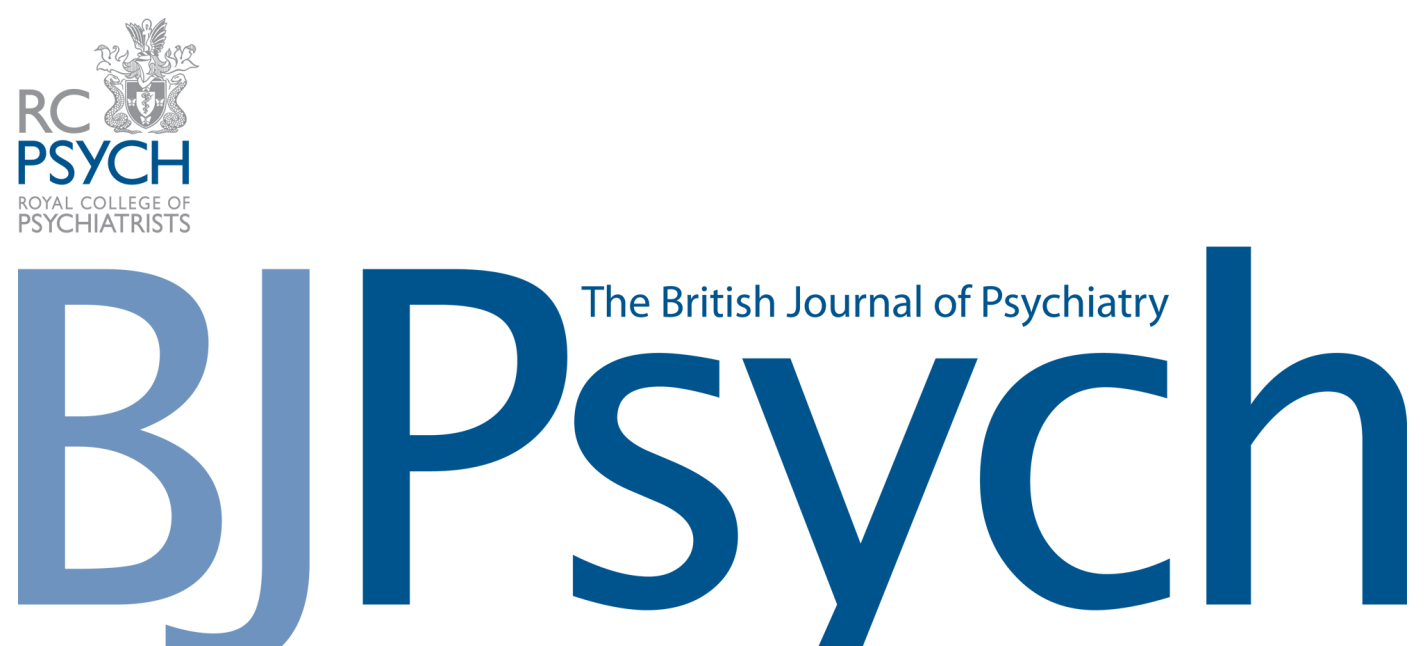

\title{
An analysis of social competence in schizophrenia.
}

A S Bellack, R L Morrison, J T Wixted and K T Mueser BJP 1990, 156:809-818.

Access the most recent version at DOI: 10.1192/bjp.156.6.809

References This article cites 0 articles, 0 of which you can access for free at: http://bjp.rcpsych.org/content/156/6/809\#BIBL

Reprints/ To obtain reprints or permission to reproduce material from this paper, please write permissions to permissions@rcpsych.ac.uk

You can respond http://bjp.rcpsych.org/cgi/eletter-submit/156/6/809

to this article at

Downloaded

http://bjp.rcpsych.org/ on August 22, 2012

from

Published by The Royal College of Psychiatrists

To subscribe to The British Journal of Psychiatry go to: http://bjp.rcpsych.org/site/subscriptions/ 
British Journal of Psychiatry, 1990, 156, 809-818

\title{
An Analysis of Social Competence in Schizophrenia
}

\author{
ALAN S. BELLACK, RANDALL L. MORRISON, JOHN T. WIXTED and KIM T. MUESER
}

\begin{abstract}
Twenty-one schizophrenics with prominent negative symptoms were compared with 37 schizophrenics without them, 33 patients with major affective disorder and 20 non-patient controls on a battery of measures including a role-play test of social skills, the Social Adjustment Scale, and the Quality of Life Scale. The negative schizophrenics were most impaired on every subscale of each measure, followed in order by the non-negative schizophrenics, affective disorder patients, and non-patient controls. The social skill measures were not correlated with positive symptom levels, but were highly correlated with measures of community functioning. The results are consistent with the hypothesis that social dysfunction results from focal deficits in social skills.
\end{abstract}

Severe impairment of social functioning is one of the hallmarks of schizophrenia. Deterioration of social relations is one of the defining diagnostic criteria specified in DSM-III-R (American Psychiatric Association, 1987), and social isolation or withdrawal and marked impairment in major life role functioning are listed as prominent prodromal and residual symptoms. While there has been widespread agreement about the existence of severe social disability for some time, there is surprisingly little data on the precise nature or the basis of the dysfunction (Wallace, 1984).

The most prominent hypothesis is that social impairments are epiphenomena which result from other more basic symptoms of the disorder, such as negative or deficit symptoms. There is considerable evidence to suggest that such symptoms as avolition, anhedonia and alogia demarcate a distinct subtype of schizophrenia (Andreasen, 1985; Carpenter et al, 1985; Crow, 1985). Patients whose illness is characterised by prominent negative symptoms have an increased frequency of structural brain impairment and decreased intellectual functioning, as well as a poorer prognosis (Johnstone et al, 1978). They also tend to have poor pre-morbid social competence and impaired social relationships (Liddle, 1987; Johnstone et al, 1979).

These findings suggest that negative symptoms play a central role in social disability. This possibility has high face validity in regard to such symptoms as blunted affect, avolition, anhedonia, and anergia. However, other negative symptoms, such as asociality and alogia, seem to be as much reflections of social impairment as causes of it. Indeed, Carpenter et al (1988) recently distinguished between primary and secondary negative symptoms, the former representing basic and enduring aspects of the illness while the latter are consequences of other factors. Thus, secondary negative symptoms could result from social disability as well as vice versa. This dichotomy has important implications for understanding the nature of the disorder and its treatment, but it has not yet been systematically examined.

A second hypothesis about the basis of social impairment in schizophrenia is provided by the behavioural model of social skills (Bellack \& Morrison, 1982; Liberman, 1982; Trower et al, 1978). According to this model, effective social performance requires the skill to perform the appropriate response, as well as the cognitive/ perceptual ability to determine what response is appropriate and the motivation to perform this (McFall, 1982). Thus, social skills are seen as necessary (although not sufficient) to produce effective social performance. The second hypothesis suggests therefore that schizophrenics have focal deficits in such social skills, and previously it has been presumed that they either fail to learn these initially or lose them after long periods of hospitalisation or social isolation. Unfortunately, the existing literature provides no sound validation for the skills model or for determining the precise role of social skills deficits in lowered social competence. The literature on pre-morbid social competence and childhood adjustment documents that many schizophrenics have long-standing impairments in role functioning. However, these studies are primarily retrospective and cannot elucidate the reasons for the faulty performance (Zigler \& Levine, 1981). It has frequently been demonstrated that social skills training, which is based on the skills model, increases skill level and improves overall functioning (Morrison \& Wixted, 1989). This provides convergent validational support for the skills model, but does not demonstrate that pre-treatment deficits were responsible for impaired functioning or that improved functioning resulted from increased skill. 
Although the most frequently cited source of support for the skills model is behavioural observations of patients engaging in social interactions, few such studies have reported separate data on a carefully diagnosed cohort of schizophrenics. Longabaugh et al (1966) found notable deficits in a sample of schizophrenic in-patients. However, their subjects had all been hospitalised for at least six years, and could have been suffering from institutionalisation syndrome rather than skill deficiencies. Argyle (1981) reported that schizophrenics have a variety of specific skills deficits, including inappropriate facial expression, gestures and posture, low rewardingness, and poor synchronising. Lindsay (1982) also found that schizophrenics have specific performance deficits, although his sample consisted of only three patients. However, Rutter (1977a,b; 1978), in a study of paralinguistic behaviour, speech patterning, and visual interaction patterns, found few differences between schizophrenics and matched groups of non-patients and patients with other diagnoses.

Despite its widespread acceptance, the evidence in support of the skills hypothesis is quite tenuous. Firstly, no studies have examined patients diagnosed according to current (DSM-III (American Psychiatric Association, 1980) or DSM-III-R) criteria. Secondly, it is not clear that schizophrenics have specific skill deficits, as opposed to a general impairment in social functioning which results from other aspects of the disorder, such as negative symptoms. Thirdly, it is also uncertain if the social impairments characteristic of schizophrenia are specific to the disorder, or are associated with other chronic disorders as well. The purpose of the current investigation was threefold: (1) to determine if schizophrenics are more socially impaired than other chronic patients or non-patients; (2) to compare the social competence of patients with and without negative syndrome; and (3) to examine the relationship of social skills to positive and negative symptoms. A secondary goal of the study was to examine the validity of role-play tests of social skills.

\section{Method}

\section{Patients and controls}

The subjects, who included 58 schizophrenic patients (21 with negative syndrome and 37 with non-negative syndrome), 33 patients with major affective disorder (29 bipolar, 4 unipolar), and 20 non-patient controls, were selected from in-patient admissions to the psychiatry service of the Medical College of Pennsylvania (MCP) at the Eastern Pennsylvania Psychiatric Institute (EPPI). Patients were considered for the study if they were 18-50 years-of-age, with no obvious evidence of organic brain syndrome, mental retardation, or alcohol or drug abuse. Affective disorder patients were required to have at least a six-month history of illness, so as to be comparable to the schizophrenics on chronicity. Patients were interviewed within several weeks of their index hospitalisation with the Schedule for Affective Disorders and Schizophrenia (SADS) (Spitzer \& Endicott, 1978) or the Structured Clinical Interview for DSM-III (SCID) (Spitzer \& Williams, 1985) by a trained psychologist. psychiatrist or psychiatric nurse. Based on these interviews and hospital records, a consensus diagnosis was reached by the interviewer and one of the first two authors (AB or RM) in accordance with DSM-III-R criteria. Approximately $20 \%$ of the structured interviews were reviewed by a third clinician in order to provide an independent check on the reliability of diagnosis. There was a 100 per cent agreement on primary DSM-III-R diagnosis for this sample.

Non-patient subjects were recruited from the nonprofessional staff and surrounding community of the hospital. Non-patient volunteers were excluded from participation if they had a history of treatment for a psychiatric disorder. Groups were matched as carefully as possible on age, socioeconomic status (SES) (Hollingshead \& Redlich, 1958), race, and sex. ANOVAs (on age, education) and $\chi^{2}$ (on sex, race) were non-significant (NS), indicating that the groups were carefully matched. However, as most non-patient controls were employed, there was a

\section{TABLE I}

Demographic variables and information about course of disorder for patients and non-patients

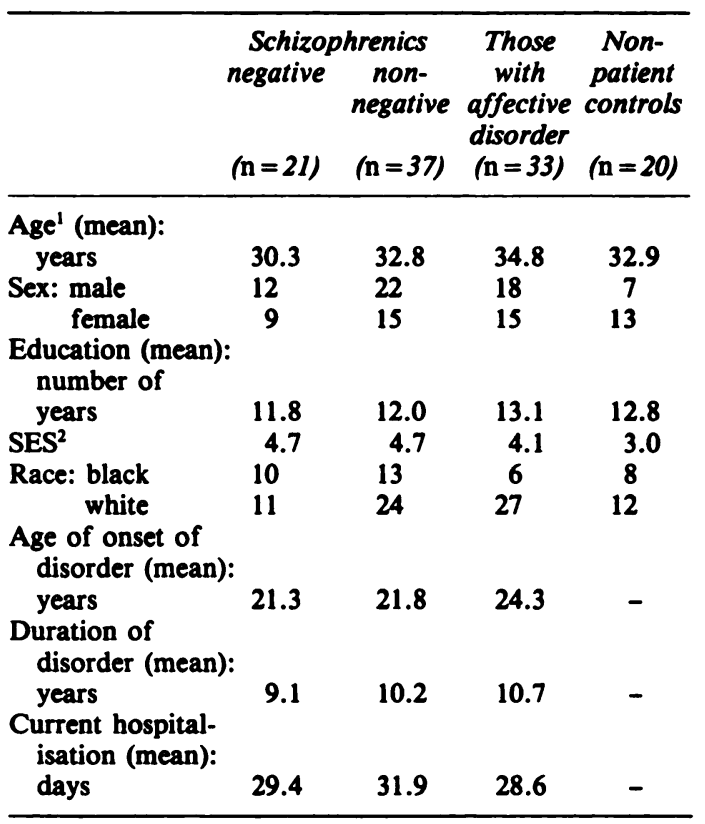

1. Patients included between 18 and 50 years-of-age.

2. Hollingshead \& Redlich, 1958. 
significant difference between them and the patient groups on SES. All subjects were paid for participation in the study.

Table I provides a summary of age, educational level, SES, race, and sex, as well as age at onset of disorder (i.e. first in-patient hospitalisation), duration of disorder, and duration of present hospitalisation for the groups. All patients were on medication at the time of testing. Overall, the patient samples are young, acute groups, with few hospitalisations before the index assessment.

\section{Structured interviews}

The diagnostic interviewer completed the Brief Psychiatric Rating Scale (BPRS) (Overall \& Gorham, 1962). All subjects then participated in a second structured interview with an interviewer who was blind to diagnosis. That interviewer rated the subject on the Scale for the Assessment of Negative Symptoms (SANS) (Andreasen, 1982; Andreasen \& Olsen, 1982), and on two measures of social role functioning in the community: the Social Adjustment Scale II (SAS) (Weissman \& Bothwell, 1976; Weissman \& Paykel, 1974), and the Quality of Life Scale (QLS) (Heinrichs $e$ $a l, 1984)$. The SAS is a self-report and interviewer rating scale which yields scores on five dimensions: 'work adjustment', which includes adjustment as a student or homemaker; 'household adjustment', which deals with relationships with household members; 'external family adjustment', or relationships with relatives outside of the household; 'social and leisure adjustment'; and 'general adjustment', which is an overall measure. The QLS is a 21 -item interviewer rating scale which provides ratings on four dimensions: 'interpersonal relations', which judges capacity to form relationships as well as the extent of social interactions; 'instrumental role functioning', which focuses primarily on occupational, student, or homemaker roles; 'intrapsychic foundations', which relates to cognitive, affective, and motivational functioning; and 'common objects and activities', which assesses participation with the objects and activities of every day life (e.g. reading newspapers, shopping, possession of a wallet, keys, watch, etc.).

Interviewers were trained and supervised by the first two authors. Approximately $25 \%$ of all interviews were rated by a second, independent rater. Reliability was satisfactory for each subscale of each measure (reliability coefficients range $r=0.77-0.91$ ) with the exception of 'household adjustment' on the SAS $(r=0.64)$.

\section{Behavioural observations}

Social skill is a construct which has defied easy measurement. Characteristically, it is defined operationally by performance on an analogue test of social interaction (e.g. a role play or structured conversation). Adequate performance on the test implies that the individual has the requisite skills in his/her repertoire, although other factors may interfere with performance in real life interactions. An individual who does not perform adequately may not possess the requisite skills, or may fail to manifest them due to confounding factors (e.g. anxiety about being videotaped). Given these limitations, behaviour on these tasks must be interpreted cautiously. However, they have been shown to be quite useful in evaluating the effects of social skills training and in discriminating high- and lowskill groups from diverse diagnostic populations (Bellack, 1979; 1983).

All subjects participated in a role-play test of social skills which was videotaped and retrospectively rated on a number of specific behavioural components. Subjects were seated in a videotape studio with a research assistant who portrayed an interpersonal partner. They enacted 12 social encounters in which the subject was required to either initiate a conversation, resist unfair treatment, or express appreciation for something the confederate did or said. Each interaction continued through three verbal interchanges (i.e. the subject was required to make at least three responses to confederate prompts).

Role-play enactments were subsequently rated on appropriateness of: gaze, speech duration, meshing (smoothness of turn taking and conversational pauses), affect, and two verbal content measures (request/compliance and praise/appreciation). Independent ratings were made of overall social skill. All ratings were made by research assistants who were blind to subjects' group status. Raters were trained on a library of videotapes from our previous research. They first learned to match criterion ratings, and then practised rating independently until each behavioural category was rated with a reliability of at least $r=0.80$. Initial data tapes from this protocol were rated independently by the primary raters, and then reviewed jointly by the raters and one of the authors to further ensure the accuracy and consistency of the ratings. One third of the videotapes (drawn proportionately from each subject group and different time points) were scored by an independent rater to provide a reliability check. Reliability was high for all categories (Pearson correlation coefficients range, 0.74-0.89).

\section{Procedure}

Clinical records of all new admissions to the MCP/EPPI in-patient units were reviewed by a research staff member, and appropriate patients were then screened using a SADS or the SCID to determine the diagnosis. Patients accepted into the study participated in the interview measures and role-play test on two separate days within one week of the diagnostic interview. Testing was initiated after the research team and the attending physician concurred that acute symptoms had remitted sufficiently for the patient to leave the ward and complete the research tasks. Non-patien subjects were similarly scheduled to complete the interviev and role-play test measures within a one-week period.

\section{Data analysis plan}

The data analysis consisted of a series of steps designed to first categorise and describe our sample, and then test the following hypotheses: (1) negative schizophrenics will be more socially impaired than non-negative patients, who will not differ from bipolars, but all three groups will be impaired in relation to non-patient controls; (2) social 
competence measures will have only a moderate correlation with symptom measures (suggesting that social dysfunction is not solely a by-product of either positive or negative symptoms); (3) role-play measures of social skills will be related to role functioning in the community.

\section{Results}

\section{Subclassification of schizophrenics}

Schizophrenic subjects were retrospectively categorised as negative or non-negative according to the criteria of Andreasen (1982). Negative subjects were characterised by scores of four (marked) or five (severe) on two or more categories on the SANS. As all subjects were receiving neuroleptics and acute positive symptoms were at least partially remitted, we did not separately classify subjects as having positive schizophrenia. Hence, the non-negative group includes patients who might fit Andreasen's positive or mixed categories. Twenty-one patients met the criteria for negative schizophrenia and 37 were classified as nonnegative. The negative group had a mean score of 3.27 (range $=9-24)$ on the five SANS scales, compared to a mean of 1.67 (range $=1-15$ ) for non-negatives. Analyses of variance indicated that the negative group exhibited significantly more symptoms on each of the five SANS categories: 'affective flattening', $F(1,51$ d.f. $)=26.50$, $P<0.001$; 'alogia', $F(1,51$ d.f. $)=13.94, P<0.001$; 'avolitionapathy', $F(1,51$ d.f. $)=60.59, \quad P<0.001$; 'anhedoniaasociality', $F(1,51$ d.f. $)=34.27, P<0.001$; and 'inattention', $F(1,51$ d.f. $)=8.1, P<0.005$.

\section{Medication and symptoms}

All schizophrenics were receiving neuroleptics at the time they were assessed. Some of the common side effects of neuroleptics, including akinesia and pseudoparkinsonism, can result in impairments which are similar to negative symptoms. As a partial check on the extent to which the negative symptoms of our subjects may have been druginduced, we compared the dosage levels of patients in the two schizophrenic groups. Dosages were first converted to chlorpromazine equivalents (Davis \& Gierl, 1984). Negative symptom patients were receiving a mean of $891.67 \mathrm{mg}$ per day compared with $883.80 \mathrm{mg}$ per day for non-negative ones. This difference was not significant $(t(49$ d.f. $)=0.05)$. Furthermore, correlations between SANS scores and dosage level were uniformly low and non-significant (range $-0.10-0.03$ ).

Descriptive statistics and results of analyses of variance for BPRS summary scores are presented in Table II. As expected, the negative schizophrenic group scored significantly higher than the other three groups on the 'anergia' factor, which substantially reflects negative symptoms. The two schizophrenic groups did not differ on any other scale, indicating that the negative group did not exhibit more symptoms uniformly. The non-negative and negative schizophrenics had mean scores of 12.41 and 14.14 respectively on the BPRS 'thought disorder' scale, indicating that most of these subjects were still actively psychotic at the time they were assessed. The affective disorder patients were less thought disordered than either of the schizophrenic groups at the time of assessment $(x=9.15, P<0.05)$, but $88 \%$ of them were psychotic at the time of admission, and $67 \%$ continued to exhibit psychotic symptoms at the time of testing (based on BPRS scores of four or more on any of the individual 'thought disorder' items).

\section{Group differences in social competence}

The basic strategy for comparing social functioning of the four groups was to conduct separate two-way, repeated

TABLE II

Descriptive statistics, F ratios, and Tukey comparisons for the Brief Psychiatric Rating Scale (BPRS)

\begin{tabular}{|c|c|c|c|c|c|c|c|c|c|c|c|}
\hline \multirow[b]{2}{*}{$\begin{array}{l}\text { Subscale } \\
\text { of BPRS }\end{array}$} & \multicolumn{3}{|c|}{$\begin{array}{c}\text { Schiz } \\
\text { negative (NS) } \\
(\mathrm{n}=21)\end{array}$} & \multicolumn{2}{|c|}{$\begin{array}{l}\text { Dhrenics } \\
\text { non-negative (S) } \\
(\mathrm{n}=37)\end{array}$} & \multicolumn{2}{|c|}{$\begin{array}{c}\text { Those with affective } \\
\text { disorder (A) } \\
(\mathrm{n}=33)\end{array}$} & \multicolumn{2}{|c|}{$\begin{array}{c}\text { Non-patient } \\
\text { controls }(C) \\
(\mathrm{n}=20)\end{array}$} & \multirow[b]{2}{*}{$\mathbf{F}^{1}$} & \multirow[b]{2}{*}{ Tukey } \\
\hline & & $\begin{array}{l}\text { (lean } \\
\text { s.d.) }\end{array}$ & Range & $\begin{array}{l}\text { Mean } \\
\text { (s.d.) }\end{array}$ & Range & $\begin{array}{l}\text { Mean } \\
\text { (s.d.) }\end{array}$ & Range & $\begin{array}{l}\text { Mean } \\
\text { (s.d.) }\end{array}$ & Range & & \\
\hline $\begin{array}{l}\text { Anxiety/ } \\
\text { depression } \\
\text { Anergia }\end{array}$ & $\begin{array}{r}8.47 \\
10.34\end{array}$ & $\begin{array}{l}(4.11) \\
(4.45)\end{array}$ & $\begin{array}{l}4-18 \\
4-19\end{array}$ & $\begin{array}{r}10.08(3.68) \\
7.95(3.60)\end{array}$ & $\begin{array}{l}4-17 \\
4-18\end{array}$ & $\begin{array}{l}8.47(3.48) \\
5.18(2.04)\end{array}$ & $\begin{array}{l}4-20 \\
4-12\end{array}$ & $\begin{array}{l}7.40(3.14) \\
4.43(0.84)\end{array}$ & $\begin{array}{l}4-14 \\
4-7\end{array}$ & $\begin{array}{r}42.69^{*} \\
18.02^{* *}\end{array}$ & $\begin{array}{c}\text { S }>C \\
\text { NS } S>A, C \\
\text { NS }>S\end{array}$ \\
\hline $\begin{array}{l}\text { Thought } \\
\text { disorder }\end{array}$ & 14.14 & $(5.62)$ & $4-25$ & $12.41(4.36)$ & $4-23$ & $9.15(4.29)$ & $4-19$ & $4.60(1.19)$ & $4-8$ & $21.56^{* *}$ & $\begin{array}{c}\text { NS S,A }>C \\
\text { NS S }>\text { A }\end{array}$ \\
\hline $\begin{array}{l}\text { Activation } \\
\text { Hostility }\end{array}$ & $\begin{array}{l}6.79 \\
7.86\end{array}$ & $\begin{array}{l}(3.08) \\
(4.09)\end{array}$ & $\begin{array}{l}3-13 \\
3-19\end{array}$ & $\begin{array}{l}6.30(2.26) \\
7.68(3.63)\end{array}$ & $\begin{array}{l}3-12 \\
3-14\end{array}$ & $\begin{array}{l}6.73(3.00) \\
6.21(2.86)\end{array}$ & $\begin{array}{l}3-13 \\
3-12\end{array}$ & $\begin{array}{l}3.60(0.88) \\
4.05(1.47)\end{array}$ & $\begin{array}{l}3-6 \\
3-7\end{array}$ & $\begin{array}{l}7.85^{* *} \\
6.77^{* *}\end{array}$ & $\begin{array}{l}\text { NS S,A }>C \\
\text { NS S }>C\end{array}$ \\
\hline Total & 44.5 & (11.1) & $23-64$ & 42.1 & $24-57$ & 34.5 & $17-51$ & $23.0 \quad(4.9)$ & $17-36$ & $627.05^{* * *}$ & $\begin{array}{c}\text { NS S,A }>\text { C } \\
\text { NS S }>\text { A }\end{array}$ \\
\hline
\end{tabular}

$* P<0.05, * P<0.0001$

1. 3, 107 d.f. 
measures analyses on the role-play data, the SAS, and the QLS, in which group served as a between-subjects variable, and the subscales of the three measures of social functioning served as within-subjects variables. The statistic used was a MANOVA approach to repeated measures analysis of variance (Bray \& Maxwell, 1985), which was calculated by SPSS Advanced version V2.0 (Norusis, 1988). These analyses allowed us to simultaneously examine both overall group differences within each domain and possible interaction effects, while controlling the number of independent tests conducted. As the subscales on the various instruments varied somewhat in scoring range and format, raw scores were normalised and converted to $z$ scores for entry into the MANOVA. Multivariate effects on each analysis were tested with Pillai's trace statistic. Because of the $z$ transformation, each social competence subscale had the same mean and standard deviation when collapsed across subject groups. Therefore, the resultant $F$ ratios were meaningless and are not discussed below.

\section{Role-play test data}

Previous research on social skill suggests that the components of role-play behaviour are substantially related to overall social competence, but that they do not individually account for a significant proportion of variance (Conger \& Farrell, 1981; Romano \& Bellack, 1980). Consequently, the component scores were summed for each subject across non-verbal (gaze, length, meshing, and affect) and verbal (praise/appreciation and request/compliance) behaviour categories. This meant that the within-subjects variables on the role-play MANOVA consisted of overall social skill as well as non-verbal and verbal skill. The group effect was highly significant $(F[3,102$ d.f. $]=23.83, P<0.001$ ), and there was a significant group by subscale interaction ( $F[6,204$ d.f. $]=2.85, P<0.05)$. As indicated in Table III, the order of means was the same for each of the variables: negative schizophrenics exhibited the least skill, followed by non-negative schizophrenics, affective disorder patients, and non-patient controls respectively. Tukey post hoc tests (across the three skill variables) indicated that the patient groups each exhibited significantly less skill than the nonpatient controls $(P<0.05)$, and the negative schizophrenics performed significantly worse than both the non-negatives and the affective disorder patients $(P<0.05)$. The latter two groups were not significantly different.

The significant interaction was examined by conducting one-way, repeated measures ANOVAs on each group. As these analyses were conducted on $z$ scores generated separately for each skill category, they reflect comparative standing of the groups on each measure rather than absolute comparisons between skill levels in each domain. The only one of the four analyses to reach significance was that for non-patient controls $(F[2,17$ d.f. $]=6.07, P<0.001)$. They were rated as proportionately more skilful than the patient groups on the overall measure than on either of the two component categories.

\section{$S A S$ and $Q L S$ data}

Results for the QLS and SAS (Table III) were similar to the results for the role-play test. On each subscale in each of these instruments, negative schizophrenics were the most impaired, followed in order by non-negative schizophrenics, affective disorder patients and non-patient controls. The MANOVA on the QLS yielded a highly significant group effect $(F[3,102$ d.f. $]=68.72, P<0.001)$ and a significant group by subscale interaction $(F[9,306$ d.f. $)=2.99$, $P<0.05)$. Tukey post hoc tests on group means indicated that all three patient groups scored significantly worse than the non-patient controls. The negative schizophrenics were rated significantly worse than the other two patient groups,

TABLE III

Descriptive statistics for social functioning measures (role-play, SAS and QLS)

\begin{tabular}{|c|c|c|c|c|}
\hline & $\begin{array}{c}\text { Schi } \\
\text { negative } \\
\operatorname{Mean}^{1} \text { (s.d.) }\end{array}$ & $\begin{array}{l}\text { enics } \\
\text { non-negative } \\
\text { Mean' (s.d.) }^{1}\end{array}$ & $\begin{array}{l}\text { Those with } \\
\text { affective disorder } \\
\text { Mean' (s.d.) }\end{array}$ & $\begin{array}{l}\text { Non-patient } \\
\text { controls } \\
\text { Mean' (s.d.) }\end{array}$ \\
\hline \multicolumn{5}{|l|}{ Role-play test of social skills } \\
\hline Non-verbal component & $0.64(1.00)$ & $0.10(0.60)$ & $-0.17(0.40)$ & $-0.56(0.31)$ \\
\hline Verbal component & $0.46(0.75)$ & $0.23(0.86)$ & $-0.07(0.69)$ & $-0.69(0.41)$ \\
\hline Overall ratings & $0.76(0.86)$ & $0.29(0.80)$ & $-0.17(0.71)$ & $-1.14(0.67)$ \\
\hline $\begin{array}{l}\text { Quality of Life Scale } \\
\text { Interpersonal relations }\end{array}$ & $-1.00(0.47)$ & $-0.23(0.70)$ & $-0.06(0.76)$ & $1.53(0.60)$ \\
\hline Role functioning & $-0.71(0.39)$ & $-0.22(0.74)$ & $-0.06(1.00)$ & $1.54(0.37)$ \\
\hline Intrapsychic foundations & $-1.26(0.53)$ & $-1.19(0.63)$ & $0.15(0.75)$ & $1.45(0.40)$ \\
\hline Common objects \& activities & $-0.61(0.95)$ & $-0.07(0.75)$ & $-0.04(0.97)$ & $1.23(0.75)$ \\
\hline \multicolumn{5}{|l|}{ Social Adjustment Scale } \\
\hline Work adjustment & $0.98(0.21)$ & $0.29(0.55)$ & $0.10(0.87)$ & $-1.39(0.57)$ \\
\hline Household adjustment & $0.85(0.57)$ & $0.27(0.57)$ & $0.14(0.92)$ & $-1.35(0.83)$ \\
\hline External Family adjustment & $0.83(0.60)$ & $0.28(0.88)$ & $0.23(0.74)$ & $-1.37(0.52)$ \\
\hline Social/Leisure adjustment & $0.90(0.32)$ & $0.29(0.56)$ & $0.20(0.77)$ & $-1.65(0.63)$ \\
\hline General adjustment & $0.92(0.42)$ & $0.24(0.70)$ & $0.11(0.69)$ & $-1.64(0.57)$ \\
\hline
\end{tabular}

1. The means were calculated using $z$ score transformations. 
which did not differ from one another. As with the role-play data, the significant interaction was examined with a series of one-way, repeated measures ANOVAs. The results indicated that the interaction was accounted for by the low scores for negative schizophrenics on the intrapsychic foundations subscale $(F[3,17$ d.f. $]=5.94$, $P<0.001)$. This scale, which consists of items such as motivation, curiosity, and anhedonia, is more a measure of negative symptoms per se than of 'quality of life'. Consequently, it is not surprising that negative schizophrenics would be rated differentially lower on this scale than on the other subscales.

Each of the scales on the SAS can be coded 'not applicable' if it is not relevant to the subject's current life situation. A majority of subjects in each of the three patient groups received such scores for either the 'work adjustment' or 'external family adjustment' scales (e.g. they were not working, did not have any contact with relatives, etc.). Consequently, the MANOVA was conducted on the remaining three scales. There was a highly significant group effect $(F[3,89$ d.f. $]=62.27, P<0.001)$, but the interaction was not significant. As with the role play and QLS, Tukey tests indicated that the three patient groups were functioning significantly more poorly than the non-patient controls, and the negative schizophrenics were significantly more impaired than either of the other two patient groups. Univariate ANOVAs were conducted on those patients who did receive scores on the 'work' and 'external family' scales, and the three patient groups were rated significantly lower on both: external family, $F(3,91$ d.f. $)=30.23, P<0.001$; work $F(3,75$ d.f. $)=45.37, P<0.001$. The negative schizophrenics were significantly worse than the other two patient groups on 'work adjustment', but did not differ on 'external family'.

\section{Social functioning and symptoms}

Hypothesis two proposed that social dysfunction was not solely a by-product of either positive or negative symptoms. In order to examine this, Pearson correlation coefficients were calculated between the social functioning measures (role play, SAS, and QLS) and the symptom measures (BPRS and SANS) for all schizophrenics combined. The results for positive symptoms, as reflected by the BPRS, appear in Table IV. The correlations between BPRS factor scores and role-play measures were uniformly low and nonsignificant (range - 0.18-0.25), indicating that there was little relationship between positive symptoms and social skills. The correlations with the SAS and QLS were more variable. While most of the correlations were nonsignificant, there did appear to be a consistent relationship between several BPRS subscales and adequacy of interpersonal relationships, as reflected on both the SAS and QLS.

A similar pattern was reflected on the SANS, although the correlations were consistently higher (see Table V). The correlations between SANS and role-play measures ranged from 0.08 to 0.55 . Not surprisingly, affective flattening had a notable impact on non-verbal skills as did anergia in the BPRS. For the most part, SANS ratings accounted for less than $10-15 \%$ of the variance in role-play behaviour which is consistent with the BPRS anergia ratings. In contrast, SANS scales were highly correlated with role functioning (i.e. SAS and QLS), in some cases accounting for more than $50 \%$ of the variance.

\section{Validity of role-play measures}

In order to examine hypothesis three (the validity of the role-play test), a series of Pearson correlations was

TABLE IV

Pearson correlation coefficients between social functioning measures (role-play, SAS and QLS) and a symptom measures (BPRS)

\begin{tabular}{|c|c|c|c|c|c|c|}
\hline & $\begin{array}{l}\text { Anxiety/ } \\
\text { depression }\end{array}$ & Anergia & $\begin{array}{c}\text { Brief Psychiat } \\
\text { Thought } \\
\text { disorder }\end{array}$ & $\begin{array}{c}\text { ic Rating Sca } \\
\text { Activation }\end{array}$ & Hostility & Total \\
\hline \multicolumn{7}{|l|}{ Role-play test of social skills } \\
\hline Verbal components & -0.17 & -0.02 & 0.00 & -0.02 & 0.07 & -0.04 \\
\hline Non-verbal components & -0.03 & 0.24 & 0.08 & 0.16 & -0.03 & 0.11 \\
\hline \multicolumn{7}{|l|}{ Ouality of Life Scale } \\
\hline Interpersonal relations & -0.03 & -0.05 & $-0.44 * *$ & $-0.40^{*}$ & $-0.38^{*}$ & $-0.49 * *$ \\
\hline Role functioning & 0.10 & -0.19 & -0.17 & -0.30 & -0.22 & -0.29 \\
\hline Intrapsychic foundations & 0.09 & -0.27 & $-0.43^{* *}$ & -0.30 & $-0.35^{*}$ & $-0.48 * *$ \\
\hline \multicolumn{7}{|l|}{ Social Adjustment Scale } \\
\hline Work adjustment & $-0.41^{*}$ & $0.37 *$ & 0.09 & 0.28 & 0.07 & 0.11 \\
\hline Household adjustment & -0.26 & 0.17 & 0.32 & $0.37 *$ & 0.13 & 0.27 \\
\hline External family adjustment & -0.07 & 0.20 & 0.29 & 0.22 & 0.42 & $0.40 *$ \\
\hline Social/leisure adjustment & -0.18 & 0.17 & 0.26 & $0.39 *$ & $0.35^{*}$ & $0.35^{*}$ \\
\hline General adjustment & -0.25 & 0.17 & 0.23 & 0.30 & $0.34^{*}$ & 0.28 \\
\hline
\end{tabular}

$* P<0.01,{ }^{* *} P<0.001$. 
TABLE V

Pearson correlation coefficients between social functioning measures (role-play, QLS AND SAS) and a symptom measure (SANS)

\begin{tabular}{|c|c|c|c|c|c|}
\hline & \multicolumn{5}{|c|}{ Scale for the Assessment of Negative Symptoms } \\
\hline & $\begin{array}{l}\text { Affective } \\
\text { flattening }\end{array}$ & Alogia & $\begin{array}{l}\text { Avolition- } \\
\text { apathy }\end{array}$ & $\begin{array}{l}\text { Anhedonia- } \\
\text { asociality }\end{array}$ & Inattention \\
\hline \multicolumn{6}{|l|}{ Role-play test of social skills } \\
\hline Verbal components & 0.19 & 0.08 & 0.18 & 0.09 & 0.12 \\
\hline Non-verbal components & $0.55^{* *}$ & $0.38^{*}$ & 0.29 & $0.36^{*}$ & 0.29 \\
\hline $\begin{array}{l}\text { Overall ratings } \\
\text { Quality of Life Scale }\end{array}$ & $0.36^{*}$ & $0.34^{*}$ & $0.46^{* *}$ & $0.32 *$ & $0.32 *$ \\
\hline Interpersonal relations & $-0.54 * *$ & -0.22 & $-0.53 * *$ & $-0.83 * *$ & $-0.36^{*}$ \\
\hline Role functioning & -0.28 & -0.24 & $-0.53^{* *}$ & $-0.43 * *$ & $-0.33^{*}$ \\
\hline Intrapsychic foundations & $-0.58 * *$ & $-0.48 * *$ & $-0.75 * *$ & $-0.74 * *$ & $-0.52 * *$ \\
\hline $\begin{array}{l}\text { Common objects \& activities } \\
\text { Social Adjustment Scale }\end{array}$ & -0.08 & -0.28 & $-0.40 * *$ & -0.16 & -0.18 \\
\hline Work adjustment & 0.33 & $0.36^{*}$ & $0.72 * *$ & $0.58 * *$ & $0.44^{*}$ \\
\hline Household adjustment & $0.37^{*}$ & 0.19 & $0.59 * *$ & $0.64^{* *}$ & 0.16 \\
\hline External family adjustment & $0.39 *$ & 0.02 & 0.21 & $0.48 * *$ & $0.51^{* *}$ \\
\hline Social/leisure adjustment & $0.52 * *$ & $0.36^{*}$ & $0.58 * *$ & $0.79 * *$ & $0.46 * *$ \\
\hline General adjustment & $0.47^{* *}$ & $0.34^{*}$ & $0.54^{* *}$ & $0.66 * *$ & $0.50 * *$ \\
\hline
\end{tabular}

$* P<0.01, * P<0.001$.

TABLE VI

Pearson correlations between role-play test and QLS and SAS for all subjects"

Role play test of social skills

Verbal Non-verbal Overall

components components ratings

\begin{tabular}{|c|c|c|c|}
\hline \multicolumn{4}{|l|}{$\begin{array}{l}\text { Quality of Life Scale } \\
\text { Interpersonal }\end{array}$} \\
\hline Role functioning & -0.42 & -0.38 & -0.53 \\
\hline $\begin{array}{l}\text { Intrapsychic } \\
\text { foundations }\end{array}$ & -0.50 & -0.57 & -0.70 \\
\hline activities & -0.36 & -0.35 & -0.40 \\
\hline $\begin{array}{l}\text { Social Adjustment Sc } \\
\text { Work adjustment } \\
\text { Household }\end{array}$ & 0.43 & 0.54 & 0.62 \\
\hline $\begin{array}{c}\text { adjustment } \\
\text { External family }\end{array}$ & 0.36 & 0.47 & 0.60 \\
\hline $\begin{array}{l}\text { adjustment } \\
\text { Social/leisure }\end{array}$ & 0.37 & 0.46 & 0.43 \\
\hline adjustment & 0.41 & 0.46 & 0.59 \\
\hline General adjustment & 0.43 & 0.47 & 0.59 \\
\hline
\end{tabular}

*All correlations significant at $P<0.001$.

calculated between role-play measures and scores on the SAS and QLS for all subjects combined. The resulting correlation matrix is presented in Table VI. The correlations were uniformly high and significant (range 0.35-0.69; the negative sign reflects the inverse scaling of the QLS).

\section{Discussion}

The results of this investigation provide strong support for the contention that schizophrenics have pronounced deficits in social competence. They were substantially impaired on verbal, non-verbal, and overall ratings of social skill, as well as on interview ratings of role functioning. They scored significantly worse than non-patient controls on each measure. They also were consistently rated as more impaired than the affective disorder patients, although the differences were not significant for the non-negative subsample. This is the first study in which a carefully diagnosed cohort of schizophrenics was clearly shown to have marked social disability in comparison with both non-patients and a matched group of patients with another chronic disorder.

The results also indicate that the impairments in social functioning are not simply secondary consequences of negative or positive symptoms. The correlations between the SANS and role functioning measures (SAS and QLS) were consistently high and significant, which is consistent with the hypothesis that negative symptoms can result in social impairment. However, the analyses of variance distinguished between patients with and without high levels of negative symptoms. Patients with prominent negative symptoms consistently showed the greatest impairments, but non-negative patients also exhibited substantial deficits on each measure. These data indicated that poor social functioning can occur in the absence of negative symptoms. 
The SANS, SAS, and QLS were all rated by the same interviewer, in part to ensure that the SANS rater had adequate information to make accurate judgements. This raises the possibility that the correlations between the three may be somewhat inflated by halo effects. However, two factors vitiate this concern. The anergia subscale of the BPRS was highly correlated with the SANS total score $(r=0.46$, $P<0.001)$. As the BPRS was rated by a different interviewer, this correlation provides an independent check on the validity of the SANS ratings. Similarly, independent ratings of the SANS, SAS, and QLS were conducted to verify inter-rater reliability. The magnitude of these reliability coefficients (range $r=0.77-0.91$ ) also suggests that ratings of the two domains were distinct and valid.

The role-play test provides data on social competence from a different domain: behavioural observation. Both the ANOVAs and the correlations suggest that negative symptoms could have a deleterious effect on social skill. However, once again, non-negative patients also exhibit marked skill deficits and the correlations between the SANS and the roleplay measures were modest in comparison to those between the former and the SAS and QLS. Moreover, the primary effect of negative symptoms on social skill components seemed to be on non-verbal behaviour, possibly reflecting the concordance between such behaviour and ratings of anergia. These data suggest that negative symptoms have a more pronounced effect on performance of social roles than on the social skills required for effective functioning. Of course, these correlational data do not specify causality or the direction of effects. Negative symptoms could be a manifestation of social impairment, as well as vice versa. Moreover, both phenomena could be mediated by some third variable. However, the data do demonstrate that social skill is not simply a result of negative symptoms.

Pearson's correlations indicate that positive symptoms do not have a uniform effect on social behaviour. Some symptoms (e.g. hostility, suspiciousness and excitement) apparently have a highly deleterious ef fect on interpersonal relationships but core psychotic symptoms (e.g. hallucinations, delusions) do not have a marked effect. Similar findings have been reported by Johnstone et al (1979) and Liddle (1987). Previous research suggests that nonnegative schizophrenia is often associated with good social adjustment between episodes (Andreasen, 1985). The validity of that conclusion apparently depends on which symptoms are examined. Schizophrenics may sometimes be able to control or compensate for delusions and hallucinations during social interactions, but cognitive and affective symptoms have a more deleterious effect.
While non-negative patients were more socially competent than negative patients, they were definitely not functioning adequately. They were significantly impaired in comparison to non-patient controls on almost every measure. It is possible that their functioning would improve as symptoms continued to remit. However, it seems unlikely that social dysfunction of the magnitude found would totally resolve. Moreover, the affective patients were also significantly impaired, despite having a different set of symptoms. These data further support the hypothesis that social dysfunction is not always secondary to a specific set of schizophrenic symptoms. It should also be pointed out that many of our subjects were suffering from some degree of positive and negative symptoms. This combination may be more pernicious than either alone, producing high levels of distress and robbing patients of the capacity to effectively cope with their discomfort.

Both positive and negative symptoms were highly correlated with role functioning, but had little relationship with social skill. Conversely, social skill was highly correlated with role functioning. Together, these findings provide considerable support for the social skills hypothesis. Social skill, as reflected by role-play behaviour, appears to have a significant effect on social functioning in the community, independent of other symptoms of the disorder. This conclusion is consistent with the hypothesis proposed by Strauss et al (1974) that social competence represents an independent component of schizophrenia, orthogonal to both positive and negative symptoms. By 'independent' we do not imply that that social functioning is unaffected by positive and negative symptoms: our data strongly argue to the contrary. However, social skill deficits can also result in social dysfunctions, including phenomena such as alogia and asociality which present as negative symptoms. Carpenter et al (1988) refer to such effects as 'secondary' negative symptoms. Similarly, in some cases 'thought disorder' might better be conceptualised as a deficit in social cognition or a communication problem (Thomas et al, 1987; Cutting \& Murphy, 1988). Thus, the poorer role functioning of some of the negative schizophrenics in this study might have resulted from more extensive skill deficits rather than from negative symptoms per se (i.e. 'primary' negative symptoms).

The data provide strong support for the validity of the role-play test. Role play performance was, to a considerable extent, independent of core psychotic symptoms and was highly related to independent measures of social functioning and interpersonal relationships in the community. Previous research has suggested that role-play behaviour is not a direct 
parallel of behaviour in the natural environment (Bellack, 1979, 1983). However, the current study documents that role-play behaviour provides an excellent reflection of overall social functioning in the community. The ratings of 'overall social skill' in particular provide a cost-efficient way of assessing a critical aspect of functioning which is not well tapped by more traditional assessment procedures.

Current data are not adequate to determine the aetiological factor underlying schizophrenics' social impairment. Problems of social learning, as proposed by the social skills model, is but one possibility: schizophrenia characteristically strikes during young adulthood, preventing the patient from mastering critical social/developmental tasks associated with heterosexual and job skills, separation from family, etc. Conversely, there is evidence that some interpersonal deficits may result from a structural or functional brain impairment. For example, schizophrenics have been reported to have marked deficits in facial affect recognition, which might result from a right-hemispheric lesion or imbalance in hemispheric dominance (Morrison et al, 1988). Data on early childhood disturbances and poor pre-morbid social functioning suggests the possibility of an insidious pathological process, rather than a problem in learning (Lewine et al, 1978; Strauss et al, 1974). In keeping with recent thinking on the heterogeneity of the disorder, it may well be that there are multiple possible pathways to social dysfunction. While data from the current investigation cannot resolve this issue, by documenting the relative independence of social skills deficits they provide substantial justification for further research on both the nature and aetiology of such deficits.

\section{Acknowledgement}

This research was supported by a grant from the National Institute of Mental Health (MH 38636) to the senior author.

\section{References}

Amerrican Psychiatruc Association (1980) Diagnostic and Statistical Manual of Mental Disorders (3rd edn) (DSM-III). Washington, DC: APA.

(1987) Diagnostic and Statistical Manual of Mental Disorders (3rd edn, revised) (DSM-III-R). Washington, DC: APA.

ANDREASEN, N. C. (1982) Negative symptoms in schizophrenia: definition and reliability. Archives of General Psychiatry, 39. 784-788.

- (1985) Positive and negative schizophrenia: a critical evaluation. Schizophrenia Bulletin, 11, 380-389.

- \& OLSEN, S. (1982) Negative vs. positive schizophrenia: definition and validation. Archives of General Psychiatry, 39. 789-794.

AROYLE, M. (1981) The contribution of social interaction research to social skills training. In Social Competence, (eds J. D. Wine \& M. D. Smye), pp. 261-286. New York: Guilford.
BELLACK, A. S. (1979) A critical appraisal of strategies for assessing social skill. Behavioral Assessment, 1, 157-176.

- (1983) Recurrent problems in the behavioral assessment of social skill. Behaviour Research and Therapy, 21, 29-42.

\& Morrison, R. L. (1982) Interpersonal dysfunction. In International Handbook of Behavior Modification and Therapy (eds A. S. Bellack, M. Hersen \& A. E. Kazdin), pp. 717-748. New York: Plenum.

BrAY, J. H. \& MAXWELl, S. E. (1985) Multivariate Analysis of Variance (series no. 07-054). Sage university paper series on quantitative applications in the social sciences. Beverly Hills: Sage Publications.

Carpenter, W. T., Heinrichs, D. W. \& Alphs, L. D. (1985) Treatment of negative symptoms. Schizophrenia Bulletin, 11, 440-452.

- Heinrichs, D. W. \& Wagman, A. M. I. (1988) Deficit and nondeficit forms of schizophrenia. American Journal of Psychiatry, 145, 578-583.

Conger, J. C. \& FArrell, A. D. (1981) Behavioral components of heterosocial skills. Behavior Therapy, 12, 41-55.

CROw, T. J. (1985) The two-syndrome concept: origins and current status. Psychological Bulletin, 11, 471-486.

CUTTING, J. \& MURPHY, D. (1988) Schizophrenic thought disorder: a psychological and organic interpretation. British Journal of Psychiatry, 152, 310-319.

DAvis, J. M. \& GIERL, B. (1984) Pharmacological treatment in the care of schizophrenic patients. In Treatment and Care for Schizophrenia (ed. A. S. Bellack). New York: Grune \& Stratton.

Heinrichs, D. W., Hanlon, T. E. \& Carpenter, W. T., Jr (1984) The Quality of Life Scale: an instrument for rating the schizophrenic deficit syndrome. Schizophrenia Bulletin, 12, 388-398. 43, 330-340.

Hollingshead, A. B. \& Redlich, F. C. (1958) Social Class and Mental Illness: A Community Study. New York: John Wiley.

Johnstone, E. C., Crow, T. J., Frith, C. D., et al (1978) The dementia of dementia praecox. Acta Psychiatrica Scandinavica, 57, 305-324.

-, Frith, C. D., GolD, A., et al (1979) The outcome of severe acute schizophrenic illnesses after one year. British Journal of Psychiatry, 134, 28-33.

LEWINE, R. R. J., WATt, N. F. \& FRYER, J. H. (1978) A study of childhood social competence, adult premorbid competence, and psychiatric outcome in three schizophrenic subtypes. Journal of Abnormal Psychology, 87, 294-302.

LiBERMAN, R. P. (1982) Assessment of social skills. Schizophrenia Bulletin, 8, 62-83.

LIDDLE, P. F. (1987) The symptoms of chronic schizophrenia: a re-examination of the positive-negative dichotomy. British Journal of Psychiatry, 151, 145-151.

LINDSAY, W. R. (1982) The effects of labelling: blind and nonblind ratings of social skills in schizophrenic and nonschizophrenic control subjects. American Journal of Psychiatry, 139, 216-219.

Longabaugh, R., Eldred, S. H., Bell, N. W., et al (1966) The interactional world of the chronic schizophrenic patient. Psychiatry, 29, 78-99.

MCFALL, R. M. (1982) A review and reformulation of the concept of social skills. Behavioral Assessment, 4, 1-33.

Morrison, R. L., Bellack, A. S. \& Mueser, K. T. (1988) Facial affect recognition deficits and schizophrenia. Schizophrenia Bulletin, 14, 67-83.

_ \& WIXTED, J. T. (1989) Social skills training. In A Clinical Guide for the Treatment of Schizophrenia (ed. A. S. Bellack). New York: Plenum.

Overall, J. E. \& Gorham, D. R. (1962) The Brief Psychiatric Rating Scale. Psychological Reports, 10, 799-812.

Norusis, M. J. (1988) SPSS/PC + Advanced Statistics V2.0. Chicago: SPSS Inc. 
Romano, J. M. \& Bellack, A. S. (1980) Social validation of a component model of assertive behavior. Journal of Consulting and Clinical Psychology, 48, 478-490.

RUTTER, D. R. (1977a) Speech patterning in recently admitted and chronic long-stay schizophrenic patients.British Journal of Social and Clinical Psychology, 16, 45-55.

$-(1977 b)$ Visual interaction and speech patterning in admitted and acute schizophrenic patients. British Journal of Social and Clinical Psychology, 16, 357-362.

(1978) Visual interaction in schizophrenic patients: the timing of looks. British Joumal of Social and Clinical Psychology, 17, 281-282. SPITZER, R. L. \& ENDICOTT, J. (1978) Schedule for Affective Disorders and Schizophrenia (SADS). New York: New York State Psychiatric Institute.

\& Williams, J. B. W. (1985) Structured Clinical Interview for DSM-III-Psychotic Disorders Version (7/1/85). New York: New York State Psychiatric Institute.

Strauss, J. S., Carpenter, W. T., Jr \& Bartko, J. J. (1974) The diagnosis and understanding of schizophrenia. Part III.
Speculations on the processes that underlie schizophrenic symptoms and signs. Schizophrenia Bulletin, 11, 61-69.

Thomas, P., Kino, K. \& Fraser, W. I. (1987) Positive and negative symptoms of schizophrenia and linguistic performance. Acta Psychiatrica Scandinavica, 76, 144-151.

Trower, P., Bryant, B. \& Aroyle, M. (1978) Social Skills and Mental Health. Pittsburgh: University of Pittsburgh Press.

WALLACE, C. J. (1984) Community and interpersonal functioning in the course of schizophrenic disorders. Schizophrenia Bulletin, 10, 233-257.

Weissman, M. M. \& Bothwell, S. (1976) Assessment of social adjustment by patient self-report. Archives of General Psychiatry, 33, 1111-1115.

— \& PAYKel, E. S. (1974) The Depressed Woman: A Study of Social Relations. Chicago: University of Chicago Press.

Zigler, E. \& Levine, J. (1981) Premorbid competence in schizophrenia. What is being measured? Journal of Consulting and Clinical Psychology, 49, 96-105.

*Alan S. Bellack, PhD, Professor of Psychiatry, The Medical College of Pennsylvania, 3200 Henry Avenue, Philadelphia, PA 19129, USA; Randall L. Morrison, PhD, The Medical College of Pennsylvania; John T. Wixted, PhD, The Medical College of Pennsylvania; Kim T. Mueser, PhD, The Medical College of Pennsylvania.

*Correspondence 